Juan Uribe Echevarría

\title{
"La Paquera", novela postergada de Mariano Latorre
}

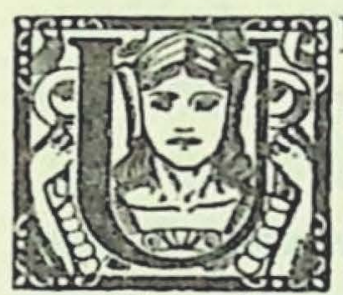

NA doble circunstancia pedagógica y racial determina la producción literaria de Mariano Latorre. Los que tuvimos la suerte de ser sus alumnos de Literatura en la Universidad, no olvidamos aquella su preocupación por fijar la raza y el paisaje del escritor.

La literatura española, en especial la moderna, era tratada por él como una suma de literaturas regionales. No se conformaba con el análisis de la producción literaria. Debíamos conocer, también, todo lo relativo al paisaje, rasgos físicos y morales, raíces étnicas, trajes, folklore, erotismo y hasta la alimentación de castellanos, andaluces, vascos, extremeños, levantinos, agotes, mallorquines, maragatos, etc.

Un mismo punto de vista llevado a los extremos de la perfección exagerada era el que nos imponía al estudiar la procedencia racial y el paisaje primigenio de los autores nacionales.

"Sin la insólita aparición de Blest Gana, cuyos antecedentes literarios no están en Chile, sino en su próxima sangre irlandesa y en la oportuna lectura de Balzac, la novela que llamamos santiaguina no habría tenido tan perfecta evolución o simplemente no se habría desarrollado" (1).

(1) La Literatura de Chile. Ediciones de la Facultad de Filosofía y Letras de la Universidad de Buenos Aires. Instituto de Cultura Latino-Americana, Buenos Aires, 1941, página 63. 
"Hay en Manuel Magallanes Moure una doble herencia lusitana que, en parte, explica la cristalinidad armoniosa de sus versos, la saudade melancólica del amor deseado y no satisfecho" (2).

"Augusto Winter, hijo de ingleses, nace en el campamento minero de Tamaya... La fuga de los cisnes, Las hualas, son poemas descriptivos, con una moraleja, a la manera de Tennyson. Rasgo típico anglosajón” (3).

"Augusto d'Halmar por sus antecedentes de raza y por sus gustos literarios se aleja de la realidad inmediata..." (4).

"Descendiente de catalanes y montañeses, Marta Brunet trajo a la novela chilena un arte equilibrado, rico de expresión y sobrio de contornos" (5).

"Ambos (Santiván y Latorre), descendemos directamente de españoles; él, de castellanos viejos, de Torrelavega; yo, de vascos de Plencia.

"Conocí al padre de Fernando. Era un hombre alto, recio, de ademanes desenvueltos y decididos. Mi padre, auténtico vasco del litoral, un pincho, como ellos dicen, era de carácter alegre y trato afable.

"Montañeses y vascos son casi vecinos en la península y así como allá se entienden, se entendieron mi padre y el suyo en la villa destartalada de Parral" (6).

A Daniel Belmar, sugestionado por el apellido le atribuyó, sin conocerlo personalmente, en prólogo famoso, una procedencia levantina.

"He pensado, primero en su apellido, Belmar, mar bello o bello mar, que no me recuerda a Castilla, trágica e improvisadora, sino a las costas levantinas o atlánticas, tocadas por la gracia de Grecia y Roma... Si fuese usted, como supongo, descendiente de un español

(1) Op. cit., página 172.

(3) Op. cit., página 173.

(4) Op. cit. página 147.

(5) Op. cit., página 118.

(6) Prólogo a Memorias de un tolstoyano. Editorial Zig-Zag, Santiago, 1955, página 7. 
atlántico o mediterráneo, estaría explicada, en gran parte, la magia de su arte de novelar, el hechizo de su prosa, fundida en tan nobles metales idiomáticos" (7).

Mariano Latorre sabía qué escritores nacionales eran blancos, mestizos o mulatos. Quiénes eran del norte o del sur, del sur extremo o del norte chico; quiénes se habían formado en la capital o en las provincias; cuáles eran las lecturas predilectas de todos ellos y sus métodos de trabajo. Cómo vivían, amaban, publicaban. La literatura chilena era presentada a los alumnos como un proceso de resonancias múltiples e insospechadas.

Se sentía un chileno reciente, interesado, embrujado por las cosas nacionales y conseguía, por todos los medios, dentro y fuera de la cátedra, contagiarnos con su entusiasmo tenaz e infatigable.

Chileno nuevo, hijo de vasco y francesa, Mariano Latorre, criollo por definición, vivió en hogar extranjero los años decisivos de su personalidad. Más importante que su nacimiento casual en Cobquecura fué su niñez en el ambiente cosmopolita de la Nueva Bilbao de hace cincuenta años y, más tarde, su juventud vivida en Valparaíso y luego en una colonia de tenderos vascos de la calle San Pablo.

En su primer libro, Cuentos del Maule (1912), Latorre, junto con retratarse él, y a sus familiares nos da el ambiente de Constitución de sus años mozos.

"En el Maule, pueblo en que predomina el elemento extranjero: tiene ese curioso cosmopolitismo de los puertos, donde las razas se amalgaman y se juntan, llegando fácilmente a transformarse y a adoptar las costumbres chilenas" (8).

"Todos ellos, los Bossi o los Dabadie, los Elliot o los Duprat, eran descendientes de marinos; gente aventurera llegada a aquellas costas en la época del puerto. ¿Cuáles eran sus ascendientes anteriores? ¿De qué tierras arribaban? Franceses, ingleses o españoles, todos

(7) Prólogo a Coirón. Editorial Zig-Zag. Santiago, 1950, página 9.

(8) La canción perdida. "Cuentos del Maule" (Tipos y paisajes chilenos). Talleres de la Empresa Zig-Zag. Santiago, 1912, página 202. 
eran capitanes o pilotos de buques mercantes que en el Maule fundaban sus familias; y allí apaciguaban su vida agitada y quizá poco limpia" (9).

Cuarenta años más tarde, ya al final de su vida, en el discurso de incorporación como miembro académico de la Facultad de Filosofía y Educación, don Mariano hizo el balance definitivo de su mitología familiar.

"En Valparaíso nos esperaba mi padre. Era Chile lo que nos rodeaba y no obstante, nada sabíamos de su entraña. Sólo de su piel, áspera, primitiva, hostil.

"Al matricularme mi padre en el liceo, mi contacto con chilenos fué mayor. En un principio no entendí a mis camaradas chilenos. Influía, sin duda, su aspecto físico. No me atraían sus rostros aindiados y sus voces estridentes; más bien me amedrentaban...

"Mi familia volvió a desunirse en Valparaíso. Mi madre regresó al Maule con mis hermanos. Yo me quedé con mi padre en Santiago. "Viví en una pequeña colonia vasca de la capital, en la calle San Pablo, frente al Mercado Central.

"De Chile, hasta ese momento, no conocía sino a los transeúntes, a las sirvientas domésticas que, con su canasto al brazo charloteaban con los pacos de punto, a los cocheros de victorias y berlinas o a las vendedoras de mote en los veranos o en las noches de invierno, a los pequeneros, con su farol lagrimoso, en una oscura bocacalle de barrio" (10).

Su modo de sentir el país, un poco desde fuera, le hacía admirar a los sabios extranjeros que iban redescubriendo Chile a los chilenos.

Latorre estudió las posibilidades novelescas que brindaba la evolución del país con el mismo tesón y hasta el mismo espíritu científico con que el Dr. Rodolfo Lenz había investigado el lenguaje, las voces indígenas y el folklore mapuche y criollo; Ricardo E. Latcham,

(9) Un hijo del Maule. "Cuentos del Maule", página 15.

(10) Autobiografía de una vocación. Edición de la Facultad de Filosofía y Educación de la Universidad de Chile. Imprenta Universitaria, Santiago, 1953, páginas 12-16. 
la arqueología; Emilio Vaisse, la literatura; los capuchinos Sebastián Englert y Félix de Augusta, lenguas y leyendas aborígenes; Federico Johow, la botánica, etc.

Aquella misma circunstancia personal y aquel tomar conciencia del trajinar de razas mezcladas en el pueblo chileno le hacían ver, por contraste, sin engaño posible, lo autóctono, lo puramente chileno en el paisaje y el hombre. De ahí su preocupación por fijar la naturaleza, el señalar hasta qué punto increíble el chileno no se sabía a sí mismo, no adivinaba sus propias posibilidades. Tenía, todavía hoy, que ser descubierto por observadores foráneos.

En un comienzo, según propia expresión, el paisaje lo conquistó más que el hombre.

Tuvo que hacer un esfuerzo gigantesco para captar a ese ser huidizo que quería llevar a sus cuentos y novelas. La pretendida homogeneidad de la raza era para Latorre sólo aparente. Con el tiempo llegó a apreciar, como pocos, las diferencias que van de chileno a chileno, de sureño a nortino, del chilote al continental, del costino al andino, del santiaguino al porteño.

También tuvo que superar rechazos íntimos, para él casi insalvables. Desde luego ni el tipo físico, ni la estructura moral eran las que hubiera preferido para sus compatriotas.

En Puerto Mayor, por boca de su pariente, el vasco-maulino, don Santiago de Algorta y Sandeliz, opina Latorre:

"Estamos en mundo nuevo y todo lo que sucede es insólito. Hay momentos en que veo a España y a Castilla y a Andalucía, pero luego no es España, sino algo extraño, impensado, extraordinariamente original. Fijémonos, por ejemplo, en el guanay... ¿No son de España sus barbas espesas, su frente redonda, y a veces sus claros ojos?, pero sus pómulos salientes y sus ojos turbios, sin mirada, recuerdan al indio..." (11).

No faltan los juicios negativos, descorazonados. Emilio Labarga, protagonista de Ully expresa su admiración por el alemán Guillermo Gunther, viejo colono del lago Llanquihue:

(11) Puerto Mayor y Chilenos del Mar. Editorial Zig-Zag, 1945, páginas 40-41. 
"En la cabeza de Emilio rejuvenece el viejo teutón. Lo ve con sus recias botas y sus barbas de oro astillando la entraña roja de un alerce o buscando en el corazón de un laurel muerto un panal de miel salvaje para mejorar el reducido almuerzo de la familia.

"Vuelve a ver al indio mentiroso o al mestizo indolente contemplando con indiferencia esta epopeya como los jotes que planean por encima de los árboles sin alma y sin edad" (12).

En El finado Valdés, nos presenta a demagogos criollos en viaje político a las minas del carbón del sur:

"Eran cuatro los parlamentarios. Dos de ellos, ejercitadas máquinas verbales. No podían desmentir su origen chileno: gruesos, panzudos, de pómulos salientes y frentes pequeñas bajo la pelambre tiesa. Cada uno ostentaba un macizo pescuezo oscuro" (13).

Sus preferencias se revelan en el retrato que nos hace de sus propios parientes, en especial, de su fabuloso abuelo Court, constructor naval a las orillas del Maule, y de su tío Aquiles:

"Era la raza popular de la Francia ese campesino bonachón y potente, de cabeza redonda y anchas espaldas, al cual pertenecen $M$. Loubt y el crítico Doumic, Lafontaine y el propio Balzac" (14).

Aquiles Elliot, hijo del Maule, se le impone como héroe juvenil:

"Aquiles Elliot, sobresalía del resto de sus parientes por su temperamento independiente e impulsivo, por la belleza de su frente y por el equilibrado vigor de sus músculos" (15).

"Aquiles, con sus rizados bigotazos de macho fuerte, colorado, con una rosa en el ojal y una cadena de oro" (16).

Las formas de vida criolla pacífica, cotidiana, le repugnaron desde un comienzo:

(12) Ully y otras novelas del sur. Editorial Nascimento. Santiago, 1923, páginas $45-46$.

(13) El finado Valdés. "Chilenos del mar". Imprenta Universitaria. Santiago, 1929, página 72.

(14) Un hijo del Maule. "Cuentos del Maule". Talleres de la Empresa Zig-Zag. Santiago, 1912, página 11.

(15) Un hijo del Maule, página 14.

(16) Un hijo del Maule, página 55. 
"En la casa chilena desmantelada y pobre como un campamento, no hay calor de hogar; el gemütlich germano, con su aroma de tradición, no puede vivir en la desnudez de las paredes, en el hielo de la falta de unión. El marido y los hijos viven en la calle; allí es donde la vida colectiva adquiere verdadera importancia. El hogar alemán es el fundamento de la vida social..." (17).

Esta actitud de reserva y, al mismo tiempo, de gran curiosidad por la vida que lo rodea se advierte en sus primeros libros, Cuentos del Maule, Zurzulita y Ully.

El caso de Mariano Latorre, dentro de nuestra literatura, es muy diferente al de otros novelistas más próximos a la entraña nacional. Manuel Rojas, por ejemplo.

Los personajes de Rojas son, casi siempre, parientes del propio autor, o seres coincidentes con su raíz última. La relación autor-personaje resulta fácil; la captación, espontánea y sin dificultades. Latorre debe averiguar mucho más. No posee la menor correspondencia inicial con los seres que quiere llevar a sus páginas. Le son extraños y se ve obligado a investigarlos como fenómenos naturales, ahistóricos.

Es lo que determina su afán ercillesco - aquí llegó donde otro no ha llegado- de descubrir y conquistar para la literatura patria zonas inhóspitas, deshabitadas, puro paisaje donde no hay ni pudo haber el menor remedo de asunto novelesco. Con este escapismo, el autor parece encubrir su huída del hombre, del personaje enigmático o insignificante.

En sus mejores libros, Cuna de cóndores (1918), Hombres y zorros (1937), Mapu (1942) y Viento de Mallines (1944), Latorre encuentra la fórmula salvadora para su difícil empresa literaria, vinculando, épicamente, el paisaje y el hombre.

"Cerro, aldea, río y estero, un Chile en síntesis, donde vivían zorros astutos que huaqueaban burlones en las noches, robándose gallinas y cabritillos y que en las primaveras poblaban el monte con el alarido de sus ruidosos amores.

(17) La mucric del cuclillo ("Ully" y otras novelas del sur), página 137. 
"Comprendí a mi rincón, le encontré un sentido oculto a esas piedras y a esos cerros y a esos hombres que vivían junto a ellas" (18).

$\mathrm{Su}$ invencible repugnancia a fórmulas criollas de vida ciudadana, que siempre le parecieron expresión de la vida falsificada, falsamente europea, de Santiago, lo hizo buscar en la gesta anónima de cerrucos, ovejeros, lancheros maulinos, chilotes embrujados, arrieros de la cordillera grande, salteadores rurales, los elementos humanos dignos de su pluma.

En su última producción, perdido ya el entusiasmo y un tanto desengañado de la vida literaria, vuelve Mariano Latorre a sus preocupaciones iniciales: $\mathrm{El}$ choroy de oro (19) (roce entre colonos alemanes y chilenos); $E l$ caracol (20) (evocación funeral de la familia de su madre); Mac Kay, el corsario rojo (21), (confrontación psicológica entre ingleses y chilenos); Miñimiñi llegó al Caleuche (22), (elementos nórdicos en una leyenda de Chiloé); Carne de Castilla, su último cuento (españoles y huasos en un campo del valle central).

En La paquera, novela inédita, afloran todas aquellas preocupaciones sociológicas, racistas y de diagnóstico nacional que hemos visto en Cuentos del Maule, Zurzulita, Ully, Chilenos del mar, y a las que dió forma ensayística y autobiográfica en sus Anécdotas y recuerdos de medio siglo (23), Lo que mis libros me contaron (24) y Autobiografía de una vocación (25).

na 12 .

(18) Prólogo a Hombres y zorros. Editorial Ercilla. Santiago, 1937, pági-

(19) Editorial Rapa-Nui. Santiago, 1946.

(20) Editorial Cruz del Sur. Santiago, 1952.

(21) "Revista Occidente" números 105 y 106, correspondientes a septiembre, octubre y noviembre y diciembre de 1955.

(22) La isla de los pájaros. Editorial Nascimento. Santiago, 1955.

(23) Revista "Atenea", número 324. Santiago, junio de 1952.

(24) Revista "Atenea", números 343-344. Enero-febrero de 1954.

(25) Edición de la Facultad de Filosofía y Educación. Editorial Universitaria. Santiago, 1953. 
La paquera fué comenzada en 1916 (26) en el auge del naturalismo zolaico en nuestras letras y terminada, en su primer manuscrito, cuatro años más tarde. Publicada a tiempo hubiera sido, cronológicamente, la tercera novela importante dentro de la corriente mencionada, junto a Juana Lucero (Los vicios de Chile) (1902), de Augusto d'Halmar y La cuna de Esmeraldo (1918), de Joaquín Edwards Bello.

Latorre nunca se decidió a llevarla a la imprenta. Era profesor y se sabía lectura escolar obligatoria. La paquera, según su opinión, le habia salido un tanto cruda y con reventones.

Poco antes de morir rehizo el segundo manuscrito, que es el que ahora comentamos. La última redacción lleva la fecha de septiembre de 1955.

María Villaseñor, normalista con título, por la Escuela Normal de Talca, es nombrada profesora de una escuela del Hospicio de Santiago, plantel dirigido por monjas de la Caridad.

Los estudiantes son niños lisiados; cojos, ciegos o retrasados mentales:

"Veíanse ciegos en abundancia, se les notaba por sus gestos torpes y la falta de armonía de las manos y los pies. Había, también, niños de patas torcidas y, sobre todo, cabezas deformes, extrañas y de variada irregularidad; ya redondas, de hinchado lomo de sandía, alargadas como melones o berenjenas, o altas, agudas como camotes..."

"Veinte niños integran mi sección. De los veinte, catorce son del Hospicio. Sólo seis han venido de afuera. Hay dos ciegos, un tuerto y un mudo. Los demás tienen las taras habituales de los niños nacidos en conventillos: enormes cabezas, con protuberancias huesosas, palideces trágicas, frías, impenetrables, y pies y manos torcidos. Recordaban la sumisión de animales domesticados, de perros dóciles. Luchando sin voluntad por sobrevivir, por recuperar la gracia de la salud.

(26) En 1916, doña Virginia Blanco, su señora, fué nombrada profesora de una Escucla Pública que funcionaba en el Hospicio de Santiago. Las impresiones de doña Virginia sobre el singular colegio movicron a don Mariano Latorre a abrir cuaderno a la futura Paquera. 
La vida misma del Hospicio, con su rígida disciplina de cuartel o de hospital, los ha moldeado como esclavos, ávidos del menor ademán o de un tono de voz que signifique una caricia. No hay en ellos rebelión alguna. Están vencidos antes de luchar, muertos antes de vivir. Más adelante van a substituir al esclavo negro de la colonia, fundidos ya en la argamasa étnica de Chile, prolongación del sirviente doméstico, hermano del inquilino de los fundos y de los mulatos de Cuba y Venezuela..."

Este es el alumnado con que debe lidiar la profesora talquina, hija de españoles. Sus compañeras de trabajo están observadas con los mismos ojos extranjeros con que Mateo Elorduy, el héroe de Zurzulita, sorprendía a los huasos maulinos:

"En ese instante me parecían iguales. Tenían el aspecto típico de todas las normalistas de hace veinte años atrás. Aspecto melancólico, resignado en la expresión, trajes pobres, usados, que denotaban una vida mísera, la búsqueda del pequeño placer, a veces el alcohol; las relaciones ocultas, si el galán pagaba la comida y, finalmente, una actitud falsa, de comediantes, frente a los profesores y las mismas compañeras".

María Villaseñor se encuentra, en el patio, con su amiga Elena, compañera de estudios en el sur, profesora, también, del extraño plantel hospiciano.

Las dos amigas van comentando, a través de los capítulos de la novela, las extrañas amistades entre monja y profesoras, la visita del obispo y el inspector escolar; las riñas entre dos tontas que baldean y friegan los comedores: Sarita y Cola.

"Sarita es pueblo, ni siquiera medio pelo, Escolástica (Cola), la hija extraviada de un ricachón santiaguino algo borracho".

La señorita Villaseñor se escandaliza con la atracción perturbadora que ejerce la hermana Antonia, de hombrunos ademanes, sobre la infeliz Felisa, normalista embrujada.

Los capítulos se suceden en una crescendo naturalista que rompe la monotonía de la vida escolar. La Cola está enamora de un policía, un paco, con el que se cita a hurtadillas. Escolástica es la paquera 
que da título a la obra. Queda embarazada de su uniformado y se convierte en el escándalo vivo de los patios hospicianos.

El ambiente anormal, malsano, del establecimiento, contamina también a otra profesora, la bella Elena, que al final huye con el cura Díaz, el negro Díaz, huasamaco con sotana y capellán del Hospicio.

"El cura Díaz es joven, de tipo muy criollo, del tipo feo del criollo, de cabellos tiesos, de un negror lustroso. Frente estrecha, ojos fríos y boca de gruesos labios.

"Con su breviario en la mano, salmodia mecánicamente el oficio de difuntos. Y a pesar de la gravedad teatral que trata de imprimir a su voz dura, desafinada, sus ojos echan chispas en dirección a Elena que se encoge tímida y halagada a la vez".

Latorre va dibujando a todos los personajes - normalistas, monjas, el cura, tontas, niños lisiados - que circulan por el Hospicio, pero de pronto su pluma parece cansarse de tanta humanidad doliente, sin esperanzas, y toma su paleta preferida:

"Desfilamos por los corredores y retornamos a la escuela.

"Es un claro sol de agosto, casi primaveral. Más cerca del calor que el veranito de San Juan.

"Gorjean los canarios, colgados en sus jaulas, de los pilares y paredones de la escuela. $\mathrm{Y}$ en el patio chirrían gorriones y diucas y hasta arrulla alguna tórtola cordillerana, emigrada de Apoquindo por el frío. El sol tibio, sedoso, repta por las paredes, tímidamente, como una lagartija de tono de oro. Las tejas oscuras, como anchas bocas, babean pequeñas burbujas de agua”.

"Al acercarme, en la monotonía de la clase y mientras mis alumnos copiaban un trozo del libro de lectura de Guzmán Maturana para las escuelas, veía un patiecillo abandonado, donde se amontonaban bancos en desuso, pizarras rotas y sillas desarmadas y joh milagro de lo imprevisto!, sobre este osario de maderas medio podridas, se alzaba la copa verdeoscura del naranjo que entreví, a través de la rejilla del dormitorio del Hospicio, la primera vez que me acerqué a la escuela. 
"A pesar del polvo que agrisaba el metal de las hojas, veíanse en la densidad del follaje las naranjas recién nacidas con su suave tono de oro claro".

Nuestro autor aprovecha lo que hay de paisaje, de naturaleza en el patio del Hospicio, se aferra como puede a lo que del campo logra llegar hasta el viejo caserón.

"Esta luz, empapada de humedad, es casi líquida. No transforma los objetos ni los desnaturaliza. Al contrario, los hace destacarse con un relieve prodigioso: los arriates del destartalado jardín, con sus rosales y camelias sin hojas, los árboles adormilados, esperando el tesoro del sol. Y los tejados negros, donde gotea la escarcha recién fundida".

"Observo a un gorrioncillo que se mete entre las maderas viejas. Salta ágil, con un leve golpe de alas, hunde la nerviosa cabecita en el suelo y se esconde. Oyó, tal vez, un ruido extraño. $\mathrm{Y}$ pienso que es la hembra, por su actitud anónima de dueña de casa que busca comida. No hay alarde de coquetería en sus movimientos o quizá no lo necesita en este momento. $\mathrm{Y}$ así es, porque, sobre ella con atrevido aleteo, vuela otro gorrión, el macho, que intenta llamarle la atención con sus arranques de aviador entusiasta.

"Y sobre las tejas, aún húmedas, reverdecidas, azulea el cielo de Chile con lejanía misteriosa".

En el medio tan extraño y repulsivo del Hospicio, el novelista medita sobre el país y se detiene en observaciones sociológicas:

"Aparentemente son iguales - se refiere a Sarita y Cola, las dos tontas-, niveladas por el Hospicio, pero en el fondo hay una diferencia esencial. Creo que eso se debe a la juventud de Chile como país. Nada hay fijo, determinado. Todo se confunde. A veces un gañán parece un caballero y un caballero tiene todas las características del gañán. Una ramera posee delicadezas de señora y una señora, inmundas apetencias de ramera. Un político, la psicología de un ratero y un ratero la sonrisa astuta del político. ¿Quién entiende esto, sobre todo si tiene que vivir en un medio tan desconcertante y tonto". 
"El paco de la Cola es un hombre de anchas espaldas, de toscas facciones de indio o mestizo. Su impermeable chorrea como un tejado. En sus bigotes tiesos el agua se detiene como al borde de un alero. Lo miramos con insistencia, lo examinamos casi burlonamente, pero él da la impresión de no vernos. Ese corpachón robusto, esas toscas manos son una muestra de la policía de Chile. Es un chileno, sin duda, como nosotras; sin embargo, nos distancia todo, físico y espíritu".

Riñen las dos tontas - Sarita y Cola- con furia desatada. Es una de las escenas más reveladoras y violentas de la novela.

"Oigo tartamudear a Sarita que, insistentemente, culpa a Cola de algo y ésta contesta olímpicamente:

"-Cola serís tú . . cola de yegua y se acerca, agresiva a su rival. Su piel se enciende, hasta adquirir el rojo de sus cabellos ásperos.

-Yo no robo a nadie - dice con voz áspera, amenazante- a mí me nació mi padre y mi madre en un fundo. Mi padre es un Arrigorriaga y Pérez Salgado, harto rico... de Huilqui, la tierra de los Errázuriz. Y tú una huacha de $\mathrm{m}$... patas pezuñentas.

"Sarita baja la cabeza, anonadada. Su gesto parece indicar que acepta de antemano la superioridad de clase de la Escolástica Arrigorriaga y Pérez Salgado, pero no se da por vencida. Hay en ella una astucia sórdida, llena de recursos, como la de un quiltro siempre en huída y siempre en ataque, si logra conseguir lo que desea.

"A buen recaudo de Cola, de su agresividad y de su escoba, dice con su voz chillona:

-Sí, me robó la plata, para dársela al paco. Todos los días habla con él. Será muy rica, sí, pero es una paquera.

"Y la Cola se siente descubierta y en ridículo al oír estas palabras. Escoba en mano se precipita sobre Sarita que huye a lo largo del corredor, buscando el amparo de las monjas sobreexcitadas..."

El curso de la novela se interrumpe con unas vacaciones. A su vuelta a las aulas, María Villaseñor se encuentra con la desagradable sorpresa de que su amiga y colega Elena y el cura Díaz han huído juntos: en busca de un escenario más agradable para sus inconfesados amores. 
A la señorita Villaseñor el ambiente de la escuela se le hace insufrible. El percance de la Cola desquicia el ambiente pacato y recatado del Hospicio. La obra termina con escenas de un naturalismo subido, provocadas por la maternidad de la tonta.

La señorita María Villaseñor consigue el traslado a otra escuela de Santiago.

Latorre capta con finura el lento sucederse de las estaciones en los patios y corredores de la escuela hospiciana.

"No, no podré olvidar el patio del Hospicio, fresco como una bodega de campo, perfumado por el aroma de los acacios en flor, y por las hortensia: que cernían, con un abrazo verdeclaro, los pilares de los corredores.

"Estremecimientos de frescos verdores en primavera y en verano, susurro de hojas movidas por el aire y salpicado de trinos de pájaros, ruido casi monótono en un comienzo, pero que, fijándose bien, era de un maravilloso sentido musical.

"El coro lo representaban los gorriones, como embriagados por sus mismos gritos. En esa lluvia de trinos, dejaba caer el chincol sus cuatro notas aisladas, nostálgicas; los dos silbidos armoniosos, el zorzal; y a veces, como un sordo toque de violoncello, el arrullo de las tortolitas, que de la cordillera bajan a los jardines de Santiago.

"En medio del patio dos araucarias parecen dormitar, agobiadas por la siesta..."

"La rutina volvió a la escuela, en el pedacito de naturaleza aprisionado en el patiecito interior del Hospicio, el naranjo cuajaba sus botones de oro y los chincoles lograban sobreponer su canto simple a la algarabía sin gracia de los gorriones.

"Y los dos pehuenes, que nacieron allí como dos huachitos mapuches, traídos de Tolhuaca o del Nahuelbuta, creíanse en el picacho de sus cerros sureños y el polen amarilleaba aún sobre las ásperas ramas del pehuén hẹmbra y entre sus ramajes, rectilíneo y acerado, asomaban los piñones sus conos oscuros, que se abrirían como bocas sedientas para arrojar el tesoro de sus semillas..." 
La paquera supera en extensión e intensidad a otros relatos metropolitanos de Mariano Latorre como La confesión de Tognina (27) y Collares (28).

Hay en La paquera, novela santiaguina del jefe del criollismo, excelencias de estilo, morosidad narrativa que se resuelve en preciosas viñetas y un tono poético, cristiano, que envuelve a los mínimos y desgraciados personajes.

María Villaseñor y su amiga Elena, la Sarita y la Cola forman un cuarteto de figuras femeninas que se graban en la mente del lector.

A los demás personajes, Latorre les concede dibujo fugaz y un tanto precipitado. Es muy posible que en una nueva redacción -acostumbraba a escribir cuatro y cinco veces sus cuentos y novelas- don Mariano hubiera sumado nuevos valores a esta novela suya, lamentablemente postergada por razones de profesión y convivencia social.

(27) Apareció en Lectura selecta. Revista semanal de novelas cortas. Santiago, 1926, número 1 .

(28) Apareció, también, en Lectura selecta. Santiago, 1927, número 51, 